\title{
R\&D Venture: proposition of a technology transfer concept for breakthrough technologies with R\&D cooperation \\ A case study in the energy sector
}

\section{Journal Article}

\section{Author(s):}

Hess, Stephan; Siegwart, Roland

Publication date:

2013-04

\section{Permanent link:}

https://doi.org/10.3929/ethz-b-000064992

\section{Rights / license:}

In Copyright - Non-Commercial Use Permitted

Originally published in:

The Journal of Technology Transfer 38(2), https://doi.org/10.1007/s10961-012-9249-8 


\title{
R\&D Venture: proposition of a technology transfer concept for breakthrough technologies with $R \& D$ cooperation: A case study in the energy sector
}

\author{
Stephan Hess $\cdot$ Roland Yves Siegwart
}

Published online: 21 March 2012

(C) Springer Science+Business Media, LLC 2012

\begin{abstract}
At times when the market demands strong active innovation, large industrial corporations with established R\&D organizations benefit from screening and developing breakthrough innovation. The ability of established organizations to absorb for future technologies is a key to successfully recognize, explore and capture breakthrough innovations. $R \& D$ Venturing is a practical way of bringing about technology transfer and exploration of future technologies through $R \& D$ cooperation, which is described in this paper by a multiple case study in the energy sector. Existing literature has been reviewed and an R\&D Venturing concept will be suggested with a number of propositions for implementation. The results of the case study strongly support that different perspectives of the concept from industry, academia and the ventures themselves have to be carefully understood. Based on the results of the case study, a conceptual framework and propositions for a successful implementation have been derived. A critical discussion of the R\&D Venturing concept shows the need for further empirical investigation.
\end{abstract}

Keywords R\&D management - Technology transfer · Innovation management · Breakthrough technologies · Technology life cycle management · Corporate venturing

JEL Classification $\mathrm{O} 31 \cdot \mathrm{O} 32 \cdot \mathrm{O} 33 \cdot \mathrm{L} 2 \cdot \mathrm{L} 3 \cdot \mathrm{L} 64 \cdot \mathrm{L} 97$

\section{Motivation}

Continuous growth in the world's economy and population, global warming, dwindling resources and high energy consumption-these are challenging our energy supply systems and raising complex questions which need to be answered through technology and innovation.

S. Hess $(\bowtie) \cdot$ R. Y. Siegwart

Swiss Federal Institute of Technology (ETHZ), Zurich, Switzerland

e-mail: hessste@ethz.ch

R. Y. Siegwart

e-mail: rsiegwart@ethz.ch 
Even the European Union's 2020 targets of achieving a 20\% renewable energy share and a $20 \%$ reduction in $\mathrm{CO} 2$ will require the energy and transportation industries to rethink their current approach to innovation. Aggressive demands for energy savings and an aging power supply infrastructure demand real breakthrough innovation and radical improvements to the inspection service, to power generation and to the distribution infrastructure. Innovation in the established energy industry is mainly connected with large companies and organizations, relevant investments and long technology development and introduction lead times. Tight deadlines, and the high-risk exposure created by the urgent need for innovation, are inevitably going to impact the industry and its dynamics.

Significant funding of innovation by state projects in universities' research institutes will increase the pressure to innovate on research institutions and technology transfer in years to come (Mowery et al. 2010). New technology transfer models between research and industry must be developed (Masterplan Cleantech Switzerland 2010) in order to screen, review, evaluate and manage the market introduction of breakthrough innovation, both in quantity and quality. Incremental technology development can be managed with the existing, continuous innovation processes already established in the industry. For breakthrough innovation and future technologies, new models have to be developed or the field could be left open to new entrants.

As far as an established company is concerned, innovation is usually developed by internal research and development (R\&D) or externally through alliances, merger and acquisitions (M\&A) or else by $\mathrm{R} \& \mathrm{D}$ co-operations with research partners within an innovation and value network (Morandi 2011). In order to control the financial risks involved in the developmental phase of innovation, internal R\&D capabilities-whether of industrial firms' processes or organizations - are tailored to existing products and markets (Ahuja and Lampert 2001). In addition, a number of control systems, processes and responsibilities are established to manage $R \& D$ investments, with the high expectations of quality and risk management involved during introduction to the market. Organizations which are thus optimized to internal efficiency are no longer flexible and cannot easily respond or adapt to new technologies and innovations (Christensen 2003): their absorption capability for external innovation is challenged. This dilemma of successful coexistence between breakthrough and incremental innovation has been investigated and discussed in the Theory of Ambidexterity (Duncan 1976).

Such a situation requires new ideas in technology screening and transfer, which can be complemented with the $R \& D$ venture concept introduced in this paper. Therefore the research question discussed follows-do R\&D Ventures, defined as an R\&D cooperation venture between incumbent firms $R \& D$ organization, academia and venture management, improve the technology transfer for breakthrough innovation to future technology markets?

Section 2 will give a brief overview about existing literature and theory background and Sect. 3 will describe the methodology. In Sects. 4 and 5 the case study and the findings will be discussed. Section 6 will suggest a generalized framework for R\&D Venturing and propositions for its implementation.

\section{Theories and background}

Technology performance over time can be illustrated in Fig. 1 by the technology lifecycle with an S-curve behavior (Foster 1987; Christensen 2003). To begin with it shows only slow improvement, owing to the unknown fundamentals often accompanied by the need for sustained scientific research. Typically the curve accelerates as insight increases, 
Technology Lifecycle from Corporate View

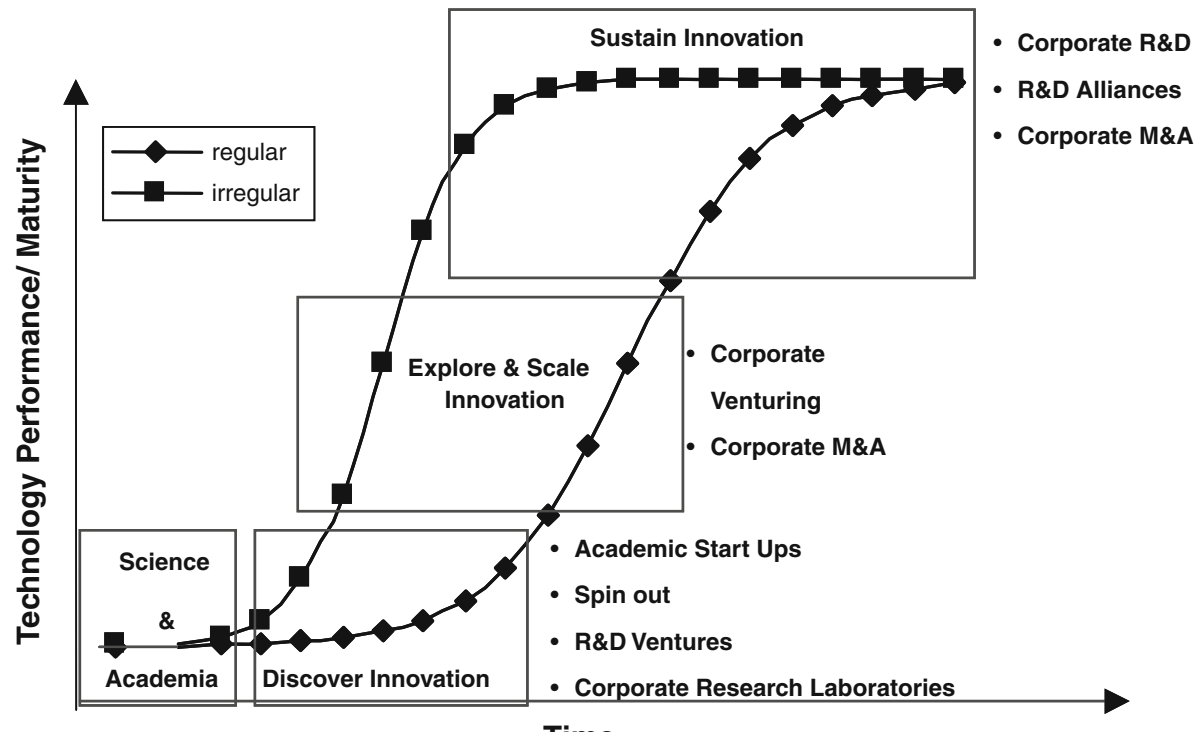

Time

Fig. 1 Schematic S-curve with regular and irregular behavior and innovation player derived from (Christensen 2003; Sood and Tellis 2005, p. 156)

engineering activities, and controlled scaling lead to higher technology maturity. Then, as the technology improves and a certain level of maturity is attained, the curve flattens out asymptotically. A natural limit has been reached. In times of sustainable innovation, this incremental behavior can be controlled by an established firm's relationship with its academic partners (Christensen 2003). In turbulent times, with considerable innovation activity within an industry, disruptive or breakthrough innovation may occur quickly in an irregular step function.

In the power industry, a time of turbulent innovation, with many competing renewable technologies jostling for position, is a real challenge to large enterprises (Schilling and Esmundo 2009; Mowery et al. 2010). Firms in this industry actively have to influence the S-curve performance by increasing their technology and environmental scanning behavior. Well-established nuclear, gas or coal technologies suddenly have to compete on a broader scale with wind, solar, hydropower or plant efficiency improvement technologies. As radical innovations are likely, and entrepreneurs capitalize on environmental change, an increase of entrepreneurial intensity is vital (Barringer and Bluedorn 1999, pp. 423-425). This is particularly true for large incumbent firms; these dynamics are further influenced by a whole range of environmental, economic, social, political, and institutional forces. A relative preference change-for example, one triggered by climate change, the high price of oil or a nuclear catastrophe, can have considerable impact on such a technological transition trajectory (Tripsas 2007).

The conventional view, supported by the theory of inertia, is that large incumbent firms struggle in an environment of rapid change and rarely introduce breakthrough technology innovation (Tornatzky and Fleischer 1990). A firmly specified ability to perform and realistic expectations about new technology and its adoption are crucial to surviving the race to innovate. Firms are likely either to ignore innovation trends or jump on them when 
it is already too late. But the fear of cannibalizing or jeopardizing existing business stems from a failure to understand the pace of market evolution. Underestimating lifecycle development means firms take uninformed decisions, and avoid taking risks or only take them reluctantly, failing to seize the advantage by making the first move (Suarez and Lanzolla 2007, pp. 379-383). Internal filters often screen out information considered irrelevant to the organization's main tasks and routines (Katz and Allen 1982; Kathoefer and Leker 2010). This can be seen, for example, within existing R\&D departments: geared towards developing current technology and increasing its efficiency, they are often adverse to risk and respond inadequately to breakthrough innovation (Henderson 1993; Kanter 1985; Ahuja and Lampert 2001; Adams 2005).

However, large firms also have real opportunities to develop and introduce breakthrough innovation. Financial and technical capabilities are crucial, including access to internal and external funds, bank credibility, a strong brand, economics of scale, technology spillover (Liang and Zhang 2011), sizeable R\&D and scientific departments, and facilities profitable enough not to be vulnerable, should development project fail. The practical implications on management to react to breakthrough innovation are manifold. These range from visionary leadership, availability for "patient money", planning flexibility, greater involvement, and the participation of wider management functions (Kanter 1985 ) to increase absorption capability, expand cooperation within a value network (Miotti and Sachwald 2003; Belderbos et al. 2004; Dushnitsky and Lenox 2005a, b; Bojanowski et al. 2011; Christensen 2003) or develop a timely entry strategy (Suarez and Lanzolla 2007).

Figure 2 structures the technology transfer models for large corporations and introduces R\&D Ventures. A firm's ability to learn and absorb for external innovation is strongly influenced by the R\&D organization and the relevant knowledge it has already built up. $\mathrm{R} \& \mathrm{D}$ plays a leading role in exploring and assimilating innovation towards new product launch (Audretsch et al. 2002, p. 157; Cohen and Levinthal 1989). It has been shown that cooperation between large, permanent $\mathrm{R} \& \mathrm{D}$ organizations and public research institutions at the front-line of technology results in higher absorption potential, positively influencing a firm's propensity to cooperate (Miotti and Sachwald 2003). It has also been shown (Chandy and Tellis 2000) that over recent decades large incumbent firms have accounted for just as many breakthrough innovations as new entrants (Sood and Tellis 2005, p. 163).

Mutual barriers which can disturb the partnership between industry and academia are: disagreement about sponsoring R\&D activities and intellectual property (IP) ownership (Sohn and Lee 2011); publication needs versus academia's lack of exclusivity; and a lack of business understanding versus a lack of academic incentives (Hall et al. 2001; O'Gorman et al. 2008). Public-private partnerships can also improve cooperation and joint research owing to industry's interest in having preferential access to talent and incentives for academia (Adams 2005; Siegel et al. 2004; Siegel and Wessner 2010). In addition, it has been shown that cooperation between academia and industry partners improves productivity and patenting activity (Woerter 2011): cooperation affords industry partners access to key faculty personnel and to students as potential future employees (Audretsch et al. 2002, p. 181).

Small and medium innovators like scientific start-ups and spin offs are considered straightforward successful when it comes to breakthrough innovation but the potential obstacles are obvious (Christensen 2003; Andersson and Lööf 2011). Agility, speed, closeness to science, niche development, and the ability to focus solely on the implementation of successful breakthrough innovation - these can counteract the vulnerability caused by economic and market barriers. It has been shown that start-ups require two to 


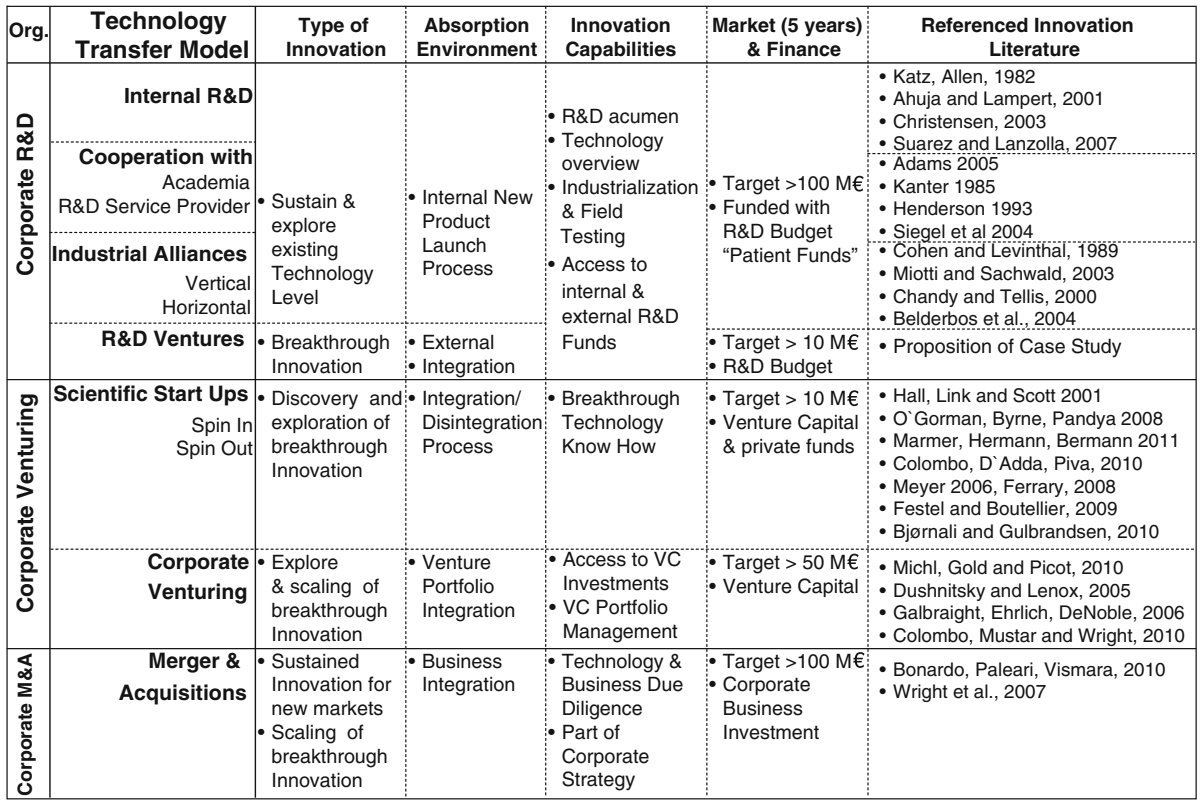

Fig. 2 Technology transfer models for large corporates

three times longer to validate technologies for their market than most founders expectindeed, the premature scaling of technologies is the prime reason for start-ups to perform worse (Marmer et al. 2011). To overcome these deficiencies it has been suggested to "use research spillover from more resource-rich firms and actively partner with organizations with technology capabilities and financial resources they do not have themselves" (Chandy and Tellis 2000, cited p.13). Large incumbents R\&D organizations have these capabilities and could be appropriate for such an active partnering approach. Although academic spinoffs are considered important for the technology transfer invented by academics, most academic patents are still used and exploited commercially by large firms (Meyer 2006). Investigation into the contribution of university research to academic start-up firms shows that the impact on their growth is higher when firms are able to detect, absorb and use the knowledge owned by academia (Colombo et al. 2010, p. 118).

The phenomenon of contradictive attributes for breakthrough innovation in large incumbent firms is also discussed in the theory of ambidexterity (Duncan 1976). Having the ability simultaneously to exploit existing technologies and explore new ones is vital for their long-term existence (Levinthal and March 1993). A hybrid theory in the domain of internal and external corporate venturing has been developed (Michl et al. 2010) to improve innovation and absorption capability by taking advantage of firms' knowledge spillover for innovative ventures (Festel 2009; Festel and Boutellier 2009). In an open innovation approach (Chesbrough 2006) strategic spin-offs are introduced and discussed in the telecommunication industry as a successful channel to incentivize internal R\&D inventors to spin out, in order to gain economic value from their research (Ferrary 2008, p. 606).

Many firms have established corporate venturing funds in order to explore new technologies and invest in rich technology sectors, and it has been claimed that a marginal benefit relative to internal R\&D can be achieved (Dushnitsky and Lenox 2005a). The role 
of internal $\mathrm{R} \& \mathrm{D}$ in corporate venturing is seen in "the leverage to gauge a venture technology feasibility and consult corporate executives to determine business and market risks" (Dushnitsky and Lenox 2005b, citation p. 618). Corporate venturing seeks innovation and growth, diversification, new technology and new markets, but its impact on the absorption capability of a firm remains uncertain (Hussinger 2010).

Corporate M\&A activities focus on larger acquisitions in new markets or innovations in the scaling phase and their business integration. The discovery phase of breakthrough technologies seems not appropriate for M\&A, as technology and product demonstration as well as scalability has not been proven by scientific start-ups. Also researchers tend to be "innovation oriented, often lacking of goal orientation" (Wright et al. 2007, p. 143; Bonardo et al. 2010) have shown that M\&A has significant exit relevance for scientific start-ups, often after IPO.

Based on the theories described above, and recognizing the private and social value of wealth creation in large firms, the need to improve the ambiguity of large incumbents and breakthrough innovations is evident. The R\&D Ventures approach should enable large R\&D organizations to also focus on discovery of breakthrough innovation in an entrepreneurial environment. Leveraging $R \& D$ acumen, technology overview, industrialization and field test capability as well as $R \& D$ funds, large $R \& D$ organization can develop breakthrough innovation with agile R\&D Ventures towards technology demonstration phase. The R\&D Venturing approach will propose merging the attributes of small firms and large incumbents through $\mathrm{R} \& \mathrm{D}$ cooperation and developing the concept of improved technology transfer.

\section{Methodology}

The research presented here involves the case studies of three R\&D Ventures in the power industry, as well as their industrial and academic partners. The cases have been selected because of the authors' awareness, involvement and therefore access to detailed and comprehensive information over a longer-term time frame. All selected cases represent a special alliance type between one industry partner and different R\&D Ventures, where the industry partner does not have similar control and influence on the alliance partner. The industry partner's impact is represented by the timing and amount of equity taken. Names have been changed to protect the companies' identities. The research encompasses a multiyear time frame which starts in the middle of the first decade of the twenty-first century and is ongoing. The data was obtained from notes taken during numerous interviews and workshops involving all relevant management positions, and also from internal and external information, such as details about the founding of the company and the make-up of the board, and R\&D reports and documentation. The case study method was selected as the R\&D Venturing phenomenon was considered new-or anyway not yet well established-and because case studies allow detailed investigation and understanding of a management problem (Eisenhardt and Graebner 2007).

This paper focuses more on understanding problems and building theory than on the testing or validation of hypotheses, which is more the realm of quantitative research (Yin 2009). Research questions were defined and became the information filter by which to qualify propositions. The successful implementation of the industrial partners' $R \& D$ Ventures, and the authors' unique insights into the cases, were essential in order to complete the research during the given time frame. 
The authors were present at-and sometimes also involved in-the development of the R\&D Venture network, and had access to all relevant management positions. This kind of action research (Greenwood and Levin 2007; Denzin and Lincoln 2005) obviously has a bias, but the authors' input was kept to a minimum: they were only engaged with the research work itself, the particular focus being on studying the player involved in the R\&D Venture Network. Considerable emphasis was also placed on the phrasing of propositions for further, more detailed research. The research may therefore be seen as a report from the front line of innovation, while the paper can be considered a mid-term, qualitative report into a wider, on-going research program involving other participants in the research area. Discussions into the proposed suggestions have begun with other major industry players who are interested in participating in the research program.

\section{Initial situation and $R \& D$ Ventures set up}

The following pages will discuss the initial situation of the industrial partners and academia, and the start-up of the R\&D Ventures as a technology transfer model.

\subsection{Industry partner}

Power plants are high-investment goods with a lifetime of between thirty and fifty years. With the liberalization of the power markets, service and maintenance of power plants have become extremely important for utilities, as they have started increasingly to focus on cost-effectiveness. Speed of maintenance, and the availability and reliability of an aging infrastructure, are key to insuring an economic and reliable power supply. Inspection technologies also play a major role in enabling a business where critical installations are heavy, hard to reach, and vital to run the plant safely. In addition, the few inspection personnel are demographically poorly distributed.

The rise of robotics, and the breakthrough innovation of using miniature cameras as advanced automated inspection technologies, innovative cleaning devices, non-destructive testing applications, system and software integration, and the possibility of robust, industrialized application-all these were inspired by the overall improvement in technology maturity achieved by industries like telecommunications and electronics. The integration and miniaturization of software and hardware-for example, in handhelds, microcomputers or medical devices-also achieved an extraordinary degree of robustness and were therefore promising concepts for the development of a wider development program of industrial inspection robotics.

The industry partner ${ }^{1}$ in this research, an established player in the power industry, is committed in the long term to further research, and has increased his environmental screening activity. An investigation study showed that no serious external suppliers for inspection robotics were available so $R \& D$ management decided to start an innovation program in that field. The industry partner was reliant on a large, well-established international product-line organization with product management, an R\&D program and execution capabilities, organized in critical technologies and encompassing about 2,000 employees. Following the companies strategy an R\&D Program has been broken down, which is executed with internal or external $R \& D$ resources. Internal $R \& D$ execution was

\footnotetext{
${ }^{1}$ Alstom Power.
} 
only considered attractive if the technology was unavailable externally or was core and therefore could not be shared.

In order to achieve a transparent R\&D capability map, around 80 critical technologies in the execution organization were described by a vision and mission statement. A critical technology of inspection technologies was only established later on, during the research time frame of the present study. However, inspection technology R\&D demands capabilities and processes, such as software development or mechatronics, which were not available within the company. Nor was it believed that externally acquired experts would be able to integrate easily into the company's R\&D environment. An external R\&D Service supplier, consultants, and in-licensing options were all considered. But again, it would have been difficult to build the appropriate internal environment for R\&D and the subsequent production resources. The company's R\&D management had also previously experienced difficulties, and were therefore wary of developing and trying to industrialize technologies where internal absorption capabilities were very limited The most favorable way of organizing the project was therefore to use an $R \& D$ Venturing approach in an economical R\&D environment, to test technology and achieve the demonstration stage within an R\&D cooperation.

\subsection{Academia}

The study also included an assessment of the technology partners in academia. Leading global technology and academic partners in robotics, sensors and water-jet technologies, $\mathrm{ETHZ}^{2}{ }^{2} \mathrm{EPFL}^{3}$ and $\mathrm{FHNW},{ }^{4}$ were found in the near vicinity of the relevant R\&D organization and contacted. A co-operation was the obvious step, although the industry partner had only very limited in-house $R \& D$ experience or available resources which would be needed to take on the development challenge. Knowing their R\&D absorption capabilities were limited, the industry partner was not willing to take the risk of building up the appropriate $\mathrm{R} \& \mathrm{D}$ organization internally. On the other hand, they did not consider the academic partner capable of advancing the development of the technology to more than laboratory demonstrators.

The industry partner began several technical studies with post-graduate students supported by scientific academics which demonstrated and supported the maturity of the different technologies. In order to find a sufficiently agile vehicle to ensure a fast industrialization of robotic technologies and produce a prototype, an R\&D Venture between industry and academia was planned. The venture was to focus solely on product development towards the demonstrator stage; it was to be funded like an internal R\&D project and eventually supported by external R\&D funding.

In addition, a business case was developed with the academic partner's technology transfer office, $R \& D$ management, and the industry partner's M\&A organization, to give the venture a perspective for a future in the robotics industry. R\&D management's intention was to restrict the R\&D Venture and to avoid going to market with immature products. When interviewed, M\&A and R\&D management confirmed that neither organization was ready. The academic partner was not used to entering joint ventures, while the industry partner was not prepared to handle the small size of such a transaction with its non-adapted internal founding mechanism, due diligence decision criteria, documentation

\footnotetext{
${ }^{2}$ Swiss Federal Institute of Technology Zuerich (ETHZ).

${ }^{3}$ Ecole Polytechnique Fédéral de Lausanne (EPFL).

${ }^{4}$ University of Applied Science North Western Switzerland (FHNW).
} 


\begin{tabular}{|c|c|c|c|}
\hline Company & Alpha & Beta & Gamma \\
\hline Business & - Industrial Inspection Robotics & $\begin{array}{l}\text { Waterjet Cleaning \& Cutting } \\
\text { Technology }\end{array}$ & $\begin{array}{l}\text {-Sensor \& Non Destructive } \\
\text { Testing Technology }\end{array}$ \\
\hline Foundation & $\begin{array}{l}\text { Founded in } 2006 \text { as an } \\
\text { R\&D Venture }\end{array}$ & $\begin{array}{l}\text { Founded in } 2007 \text { as Spin } \\
\text { Off and turned into an R\&D } \\
\text { Venture in 2008 }\end{array}$ & $\begin{array}{l}\text { - Founded in } 2009 \text { by } \\
\text { Management; R\&D } \\
\text { Venture in negotiation }\end{array}$ \\
\hline Ownership & $\begin{array}{l}\text { - Management } 25 \% \\
\text { - Academia } 24 \% \\
\text { - Industry Partner } 51 \%\end{array}$ & $\begin{array}{l}\text { - Management } 41 \% \\
\text { - Academia } 10 \% \\
\text { - SMI-Partner } 19 \% \\
\text { - Industry Partner } 30 \%\end{array}$ & $\begin{array}{l}\text {-Management } 57 \% \\
\text {-Academia } 43 \%\end{array}$ \\
\hline Employees & $\cdot 20$ & $\cdot 6$ & $\cdot 4$ \\
\hline Patents & $\cdot 6$ & - 6 & $\cdot 4$ \\
\hline Set Up Conditions & $\begin{array}{l}\text { - All IP by industry partner with } \\
\text { unlimited royalty free license back } \\
\text { - Two year "R\&D only" restriction } \\
\text { - Non compete in power market } \\
\text { - Six years business case in } \\
\text { adjacent markets }\end{array}$ & $\begin{array}{l}\text { - All IP by industry partner } \\
\text { with unlimited royalty free } \\
\text { license back } \\
\text { - Non compete in power } \\
\text { market } \\
\text { Shares Infrastructure with } \\
\text { Academia }\end{array}$ & $\begin{array}{l}\text { - IP is licensed from } \\
\text { academia and generated } \\
\text { on R\&D purchase order } \\
\text { from industrial partner } \\
\text { - Bought out } \\
\text { infrastructure from } \\
\text { academia }\end{array}$ \\
\hline
\end{tabular}

Fig. 3 Table comparison of the investigated R\&D Ventures

and management awareness. If the R\&D venture was going to happen, absolute commitment of both the management teams involved was essential.

At first, all the R\&D Ventures relied on the intellectual property of the academic partners. However, there was no discussion about licensing fees, as the academic partners would be directly benefiting as shareholders. Further benefits to the academic partners included attracting academic talents to move into high-tech firms in the vicinity and scope of their research; strong research cooperation externally funded by the R\&D Ventures and industry partners; and the anticipated innovation feedback.

Figure 3 summarizes the R\&D Ventures set up in a table.

\subsection{Alpha an R\&D Venture in the inspection service industry}

Alpha Joint Venture was founded in 2006 as an R\&D Venture in the inspection robotics industry between an established power generation service company as the industrial partner, and an academic partner. Alpha was established to pick up the latest breakthrough technologies in the academic sphere and find the fastest way of reaching the demonstrator phase. It was stipulated in the shareholder agreement that Alpha was not allowed to market any products for the first two years of its existence. Only R\&D efforts funded by the industrial partner and heading towards industrial product proof would be accepted. For two years Alpha was therefore a pure R\&D company, without any focus on supply chain or market development. However, a six-year business case was developed between the start-up and the industrial partner, showing the path of the post-development phase, which led towards the successful leverage of the developed inspection products into adjacent non-power markets.

The industry and academic partners and Alpha management are all shareholders of the joint venture. The industry partner owns a majority $(51 \%)$ but the academic partner $(24 \%)$ and Alpha management (25\%) also own a significant number of shares, making a strong impact on the start-up's development and decisions. Alpha is located in the local science park so as to allow a close operation between academia and industry. It was decided that IP 
would be with the industrial partner, while a royalty-free, unlimited license guarantees Alpha's long-term existence. The shareholder agreement restricts Alpha in a non-compete clause to not enter the power market without the industry partner. However Alpha's very aggressive business plan for the non-power market determines its financial success. The interaction between Alpha and the industry partner's R\&D, engineering, and special field service organizations was set up to ensure that stability and field experience of products was of prime importance.

\subsection{Beta an R\&D Venture in the manufacturing industry}

Beta is active in the manufacturing industry as a leading water jet cutting and cleaning product and service provider. It was founded as a cooperation in 2007 between an academic partner-FHNW and a small and medium enterprise in the regional manufacturing industry. The academic partner had achieved a state-of-the-art position in the development of water jet technologies, the application of which in the power industry significantly reduces the speed of overhaul and maintenance, and increases efficiency after plants have been recommissioned. Beta's founding as an R\&D Service provider was supported by the same industrial partner which had founded Alpha; however, this time, the industrial partner did not start the company up as a shareholder but requested specific R\&D services in water jet technology.

Like Alpha, Beta is located in a local science park and works in close cooperation with academic institution. In 2008 the industrial partner bought a minority share of $30 \%$ from the management of Beta and the SME partner, thus turning Beta into an R\&D Venture with the task of developing industrial water jet demonstrators and products. Beta was free to start marketing and sales activities in 2010 although three years of pure R\&D were needed until the first products could be demonstrated. Beta shares infrastructure with its academic partner and works in an innovation network with Alpha to develop automated cleaning applications for inspection robotics in the power market.

\subsection{Gamma an R\&D Venture in the sensor industry}

Founded in 2009, Gamma is owned by academic founders who wanted to build a market position in the sensor market for non-destructive testing, an important technological development in the inspection industry of power plants. Although Gamma works in the same innovation network as Alpha, Beta and the industrial partner's R\&D, it is an independent company. Gamma is currently developing new technologies in the miniaturization of sensor products, which will reduce the weight but improve the application and technology performance of robotic products. In recent years, the company's R\&D has been actively working to reach the product's demonstration phase. As the industry partner owns the intellectual property of the work done, as stipulated in the purchase order contracts, but cannot acquire the know-how, negotiations were started to turn Gamma into an R\&D Venture.

The risk involved in working in the breakthrough technology area with a small, nonredundant start-up lies with the industry partner. In an R\&D customer role, he invests in the research and has to rely on a small, possibly unreliable enterprise, without being able to acquire the know-how himself. Therefore, it is obvious that at some point, depending on how risky the investment is, the industry partner might give up on the cooperation or else show an interest in engaging further with the company, for example as an R\&D Venture. This way, he gets a second handle and can control the management of the start-up as a shareholder and board member, thus securing his investments. The industry partner, on the other hand, ensures the start-up management better access to his own R\&D management, 
and achieves control over operational issues at a working level. In this way, the R\&D Venture is considered a mutual commitment for R\&D cooperation between small, agile, highly innovative companies and established, experienced enterprises.

\subsection{R\&D Ventures shareholder agreements and boards set-up}

The shareholder agreement was set to describe the contractual basis of the joint research venture and its board of directors. Share distribution of the R\&D Ventures is clearly defined in the shareholder agreement, and the EBIT $^{5}$ factor of the annual due diligence will be used to evaluate the actual value of the venture in the event of dilution of capital or trade exit. Exit, preemption, refusal, stipulated damages and liquidation conditions and their impact on shareholders are also carefully defined. In addition, a non-compete agreement, licensing of intellectual property, the use of brands, and external communication are all defined to protect individual parties and describe a cooperative approach to market.

All the boards have meanwhile experienced changes in their skill set and capabilities. From the outset, it was the intention to connect external SME representatives to the board of the R\&D Ventures in order to tap into small entrepreneurs' experience. For Alpha this was implemented by the employment of a local representative, while in Beta the representative was a shareholder from the founding team. Alpha experienced a couple of natural fluctuations in the set-up of the board, which affected the president, the academic representative, and legal and R\&D representatives. However, new skills were selected carefully and commonly chosen. These new capabilities have enriched the working structure and have not jeopardized the performance of the board or the management and operation of the R\&D Venture.

\section{Practice experience and findings}

\subsection{R\&D Venture network set up}

The first, externally hired R\&D responsible for the industry partner was tasked with setting up the innovation program for the advanced inspection technologies, defining the size, scope and timeline. Clearly defined by the industry partner's R\&D management and reporting directly to them, his task was to set up a network, rather than an internal R\&D organization.

Experience A: Dedicated R\&D resource

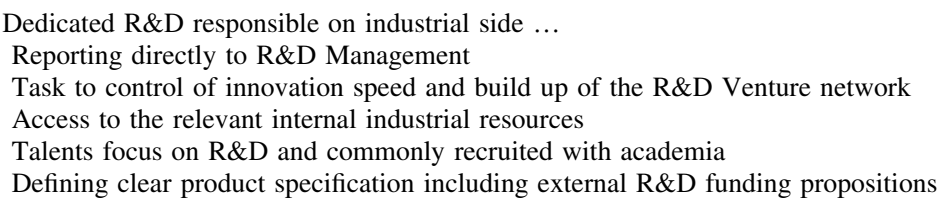

In the planning and foundation phases, Alpha was not represented by management; the partners themselves started a hiring initiative to find a chief technical officer (CTO) and R\&D staff, which were all discovered in the vicinity and network of the academic partners. The CEO joined Alpha one year after it was founded so that there was sufficient time to develop production and marketing strategy and organize the eventual go to market.

\footnotetext{
${ }^{5}$ EBIT Earnings before Interest and Taxes.
} 
As the real impact of water jet technology was unclear at the outset, the industry partner initiated the foundation of Beta separately, without becoming a shareholder. Hiring activity focused on R\&D personnel educated by the academic partners, every R\&D Venture starting with a clear R\&D specification and product target definition. The product development quality process was carried out by the industry partner, who also funded and reviewed activities. Externally funded R\&D programs were successfully launched with the academic partners in all areas of development, made easier by the fact that academia, industry and the young technology start-up were involved in an eye-level R\&D cooperation.

Experience B: Technology acceptance

Technology acceptance and the absorption capability of the industry partner increases by ...

Build up of internal $R \& D$ resources

Interaction between the R\&D Ventures and industry experts

Knowledge Sharing and acceptance of interdependence

Tailored processes towards speed and agility

Figure 4 shows the development of the R\&D Venture Network head count to date. The initial focus of ramping up the program was on the innovation network within the R\&D Venture. Then, after two or three years, the ramp-up also began within the industrial partner's R\&D organization, because the steering of the R\&D program had reached a size which made it impossible for one person to manage, both in terms of capacity and experience. To keep up with the speed of innovation and guarantee a controlled and secure ramp-up, the industrial partner decided to build up its expertise, focusing exclusively on inspection technology rather than on robotics, water jet cleaning or sensor technologies. These are to date the R\&D venture's area of competence, and interdependence is vital to maintain speed and agility. The critical technology of the inspection technologies was then introduced to the industrial partner's R\&D execution organization.

All network partners share knowledge, and interviews have shown that this exchange of R\&D experience, product strategy and product development with the industrial partners was absolutely crucial for the innovation speed the network achieved. The strong interaction with experts from the industrial partner-in all areas, but particularly within power plant field service and engineering-was of great importance for the R\&D Venture to

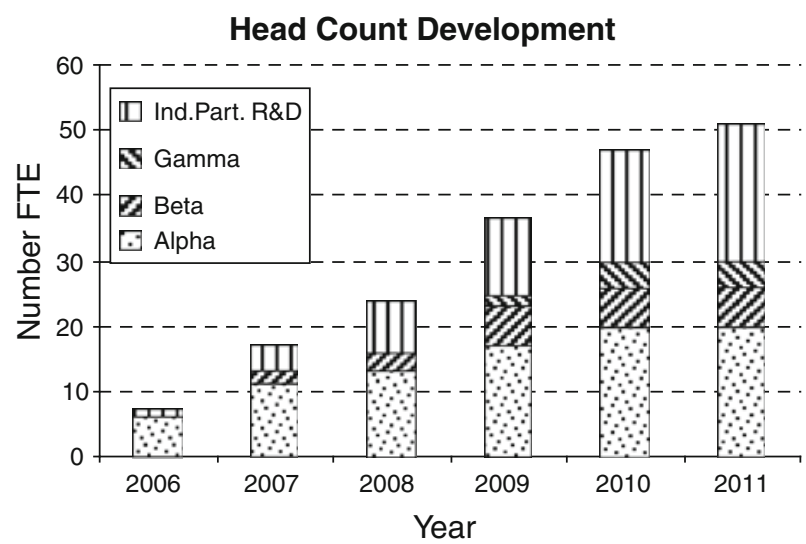

Fig. 4 Head count development of the R\&D Venture network in number of full time equivalents between 2006 and 2011 
deliver the expected technology and product applications. In return, feedback from those organizations was very positive, emphasizing in particular the visible performance and delivery of the R\&D Venture Network. Internal processes, workflows and tools were selected and tailored to create and maintain an agile, straightforward environment.

Experience C: Administration and licensing

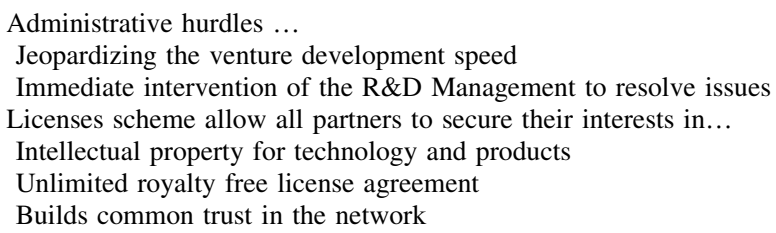

Large organizations have a strong tendency to regulate and control. In the joint venture situation Alpha management found it difficult to keep the pace of speed of a small start-up. In a joint venture situation with the majority share held by the industrial partner, Alpha experienced some conflict. This ultimately jeopardized the speed of innovation, particularly in financial consolidation and human resources management, which overloaded their administrative and management resources. These issues could only be solved by the eventual intervention of Alpha's board, with the industry partner's representatives from $\mathrm{R} \& \mathrm{D}$ and business development clarifying the situation with the internal industrial partners organization. The overall focus agreed by all stakeholders was on agility and a speedy attainment of the product demonstration phase. Thus, a special, less administrative treatment of Alpha as regards financial consolidation and human resources management could successfully be achieved.

\subsection{Product industrialisation}

Success of economic enterprises would be measured in financial results, whereas for early stage breakthrough innovation, development of technologies thoroughly protected with IP is key. Figure 5 shows innovation activity, measuring the annual number of patent priority filings between 2006 and today. As defined in the shareholding agreement with Alpha, all patent applications were filed with the industrial partner's IP organization, with the R\&D Venture receiving in return a royalty-free, unlimited license. The ramp-up of intellectual property came from the network; however, as it was difficult to identify invention ownership, a certain number of patents was also filed by the industrial partner's own internal R\&D organization. Nevertheless, all patents were licensed reciprocally between Alpha and the industrial partner.

\section{Experience D: Innovation drop}

Innovation drop because of product industrialization...

Avoid effort underestimation in business plan by cooperation; academia/industry

Control of R\&D resources head count

Careful build up of R\&D Venture engineering resources and organization

Support in field and prototype test from the industry partner accelerates

Avoid premature product entry into scaling phase 

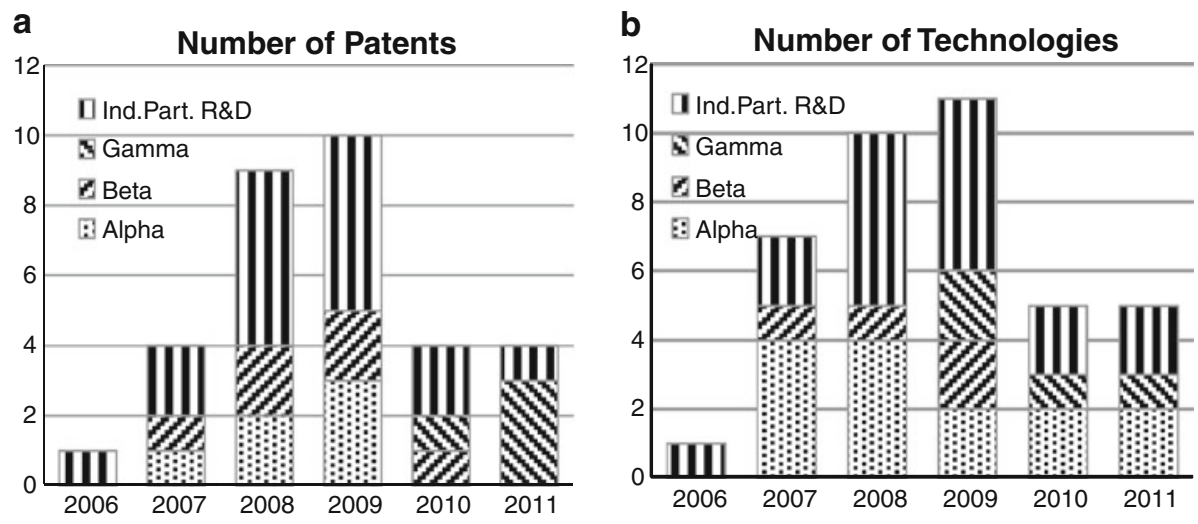

Fig. 5 a Patent applications of the R\&D Venture network 2006-2011. b Number of technologies developed in the R\&D Venture network between 2006 and 2011

Of special interest is the drop in innovation in recent years, apparent in the patent application graph above. In order to back up the finding, Fig. $5 b$ shows the number of technologies developed by the network from 2006 to date. Based on literature (Tornatzky and Fleischer 1990, p.20) a "Technology" has been defined as a technology which has successfully achieved the demonstrator phase in one product application. Technologies as defined build a technology platform out of which a number of products can be developed. For an inspection robotic example which follows a modular technology concept, one inspection robotic product will consist of a number of technologies, for example multimotor control, drive module, parallel kinematics, line following, high-adhesion module or climbing wheel, which build the basis for further product developments.

The annual distribution of technologies successfully developed supports the findings shown in the patent distribution, and an innovation drop can be assumed. The reason for this was discovered in the workload distribution within the network. Figure 6 shows the head count development in detail for Alpha and Beta in Full Time Equivalents (FTE). Both tables reveal the effects of industrialization and the build-up of engineering work forces within the R\&D Ventures. After a two to three years sheer R\&D phase of the main technologies product demonstration could be presented and first applications were tested in the field. Particular in the power industry where technologies have to be applied in a harsh and rough environment the industrialization However the industrialization towards a robust product or system application, which can be marketed and produced in a appropriate size, needs a shift in resources from R\&D to engineering and product application, supply chain, marketing and product service work forces. All the players involved in the development of the original business case for the R\&D Ventures had underestimated the industrialization phase in terms of time and the demand on resources. Once the ventures realized that their $\mathrm{R} \& \mathrm{D}$ organization was unable to fulfill their industrialization demands, they suggested a reorganization. As the business case of the $R \& D$ Ventures was restricting the growth in resources, internal $R \& D$ personnel moved over to the engineering organization, which had by then been proposed and built. Also the first exchange of resources between Alpha and the industrial partner took place during this phase. Because of the restriction, the industrial partner saw the need for a longer timeline, however his internal $R \& D$ demands were consistently being met and first other external customer had been successfully approached. 

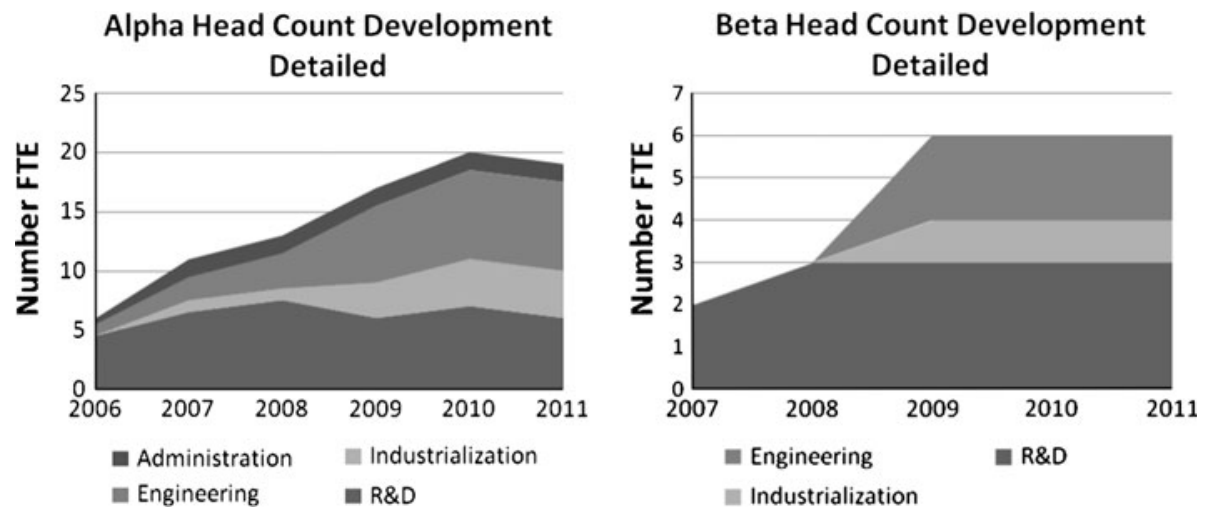

Fig. 6 Alpha and beta detailed head count development between 2006/2007 and 2011

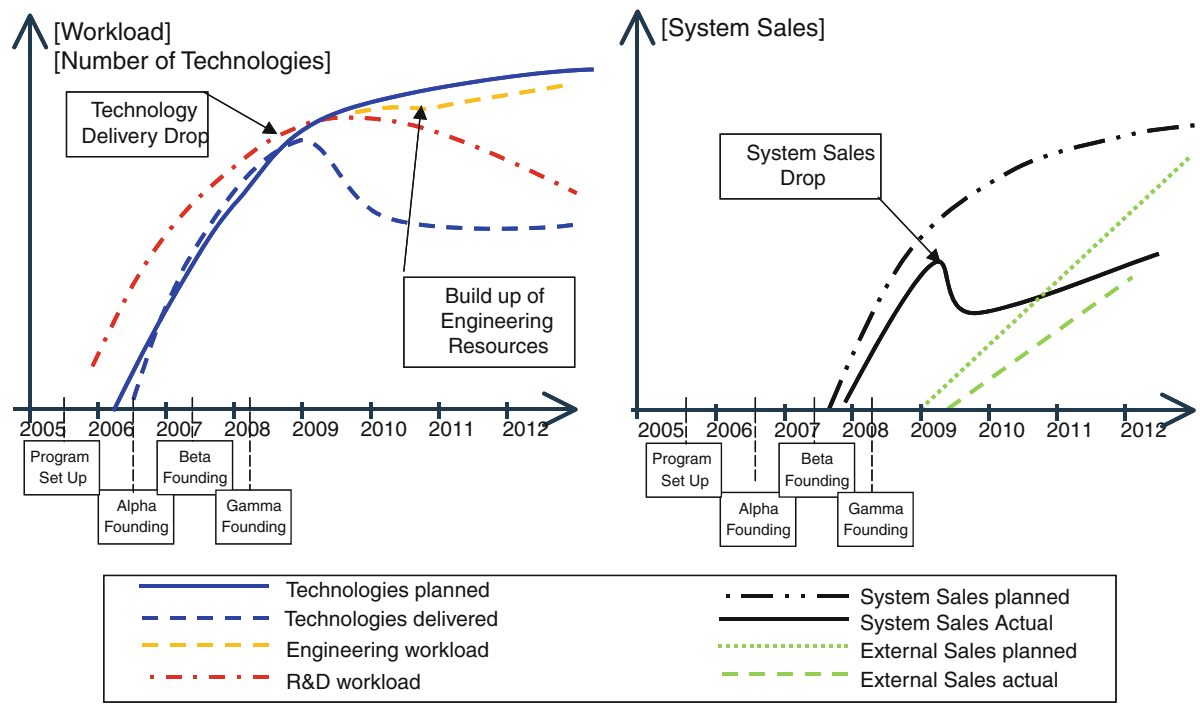

Fig. 7 Planned and achieved qualitative development of the R\&D Venture Network between 2005 and 2012

Figure 7 shows the overall qualitative development of the R\&D Venture Network from 2005 to date. All data is validated with numbers. This represents the real behavior of the development and consistently supports what has been discussed above.

Starting with a straightforward R\&D workload increase, the network's technology delivery also increased as forecast. As planned, system sales within the network were delivered with a reasonable time gap. The quality of the estimated budgets was also satisfactory until the effects of the underestimated engineering workload were felt: with the extra engineering effort required, the drop in both technology delivery and network system sales was felt, due to restricted workforce capacity and the attempt to keep to estimated business plans.

It should be noted that for breakthrough innovations these restrictions could not be compensated simply by increasing the budget or resources-for example, by using 
corporate venture capitalists, as it would have increased risk. In the early stage of technology development, dependence on single resources and their capability is high and limiting the speed of innovation. In an established firm, these restrictions could have been eliminated and the head count bumped up; however, costs and the risk of the project's failing would also have increased. Smaller stand-alone start-ups might not have been able to survive this planning gap. In case of Alpha, an about three year period of technology development has been followed by an about two year industrialization phase. Without the industrial partners interest and long-term, "patient" R\&D investment in the technology outcome, his ability to support industrialization e.g. with power plant field-test capability and engineering know how, this phase could have been longer.

In interviews, the $\mathrm{R} \& \mathrm{D}$ management considered this innovation drop an often underestimated time effort after the validation phase, in which product performance is increased and flaws cleaned up in order to start an efficient scaling phase. This phase is usually cost intensive and crucial to control the risks of bringing the product to market and avoid premature scaling. Experienced organizations' experience of product industrialization helps control the risk, but for breakthrough technologies in the engineering organization, this does not exist and costs can spiral uncontrollably. For R\&D Ventures the cost structure is transparent and limited by the business case. The delay depends on the availability of a small number of highly educated staff resources, which cannot quickly be increased. Time to market suffers but comparatively costs can be kept under control. The scaling starts only after technology industrialization. Premature scaling is a common reason for the failure of standalone start-ups, because they cannot to bear the costs of a normal short-term business plan and are tempted to jump into the scaling phase too early.

Experience E: Market approach

Successful market approach depends on...

Business Case with a wide technology and product application range

Thoroughly industrialized products

Professional behavior of the R\&D Ventures backed up \& educated by the industry partner

Market credibility of the R\&D Venture increases with appropriate communication of the partnership e.g. brand or shareholder ship and leverage of the know how learned into other industries

The initial business case for the R\&D ventures was showing a strong technology and product opportunity in adjacent non power markets, which were allowing the R\&D ventures to leverage the lessons learned after delivering industrialized products for the power market. This is a key decision criteria when going for R\&D Ventures.

Using the industrial partner's brand, show-cases and experience, Alpha successfully acquired an order backlog of relevant product revenues in the Oil \& Gas, Marine and Food Industries. By this time, Beta and Gamma had also become active in the non-network market in the automotive and jet engine industries. Customer interviews confirm a highly professional approach to market of the network's R\&D Ventures. The technologies have so far been received with interest—confirmed by the number of orders-and the products released seem robust. This can be explained, that all technologies are tested with the industry partner user and industrialized carefully in the power market. But also the exposure of the R\&D Ventures to a professional environment was educational from the beginning. For example the R\&D Venture employees were participating in the standard industry partners education programs like an environment, health and safety course for onsite power plant activities and were continuously interacting with experienced power plant field service staff on site or with professional power market management and sales 
personnel. R\&D Venture management's response to the innovation drop shown above was to reorganize and build up the engineering and marketing departments and secure a second release of new R\&D programs with the academic and industry partners. This further built up the technology platform and developed new product applications.

The R\&D Venture network achieved significant improvements in the power service inspection business. Quite a number of new inspection technologies have been introduced to the market improving the efficiency of the components, e.g. an 1-2\% efficiency increase of a turbo compressor after introducing new cleaning and overhaul technologies could be achieved. With the introduction of new automation robotics the inspection service personnel of power plants was less exposed to difficult EHS (environment, health and safety) situations, the operation efficiency of scarce inspection personnel was improved and the overhaul time of a plant inspection was reduced by faster access to the inspection target areas, e.g. by avoiding scaffolding or extensive machine dismantling and parts transport off site. The R\&D Ventures managed the knowledge and capability leverage and applied these technologies in energy transmission and distribution networks, renewable energy, hydro and other energy storage sites and even to railway inspections. Their market success in the oil and petro-chemistry industry was by showing that replacing complex life time inspections with difficult EHS exposure like radiography for certain high investment plant components could be achieved and reliability and availability improved.

The rise of external system sales after a market evaluation time were showing a global demand for the products and with establishing reliant customer relation, particular with the acquisition of multiyear contracts and additional staffing, the confidence in products and its delivery has taken up again. All R\&D Ventures discussed above are entering their targeted markets with leading edge technology still ahead and superior to competition.

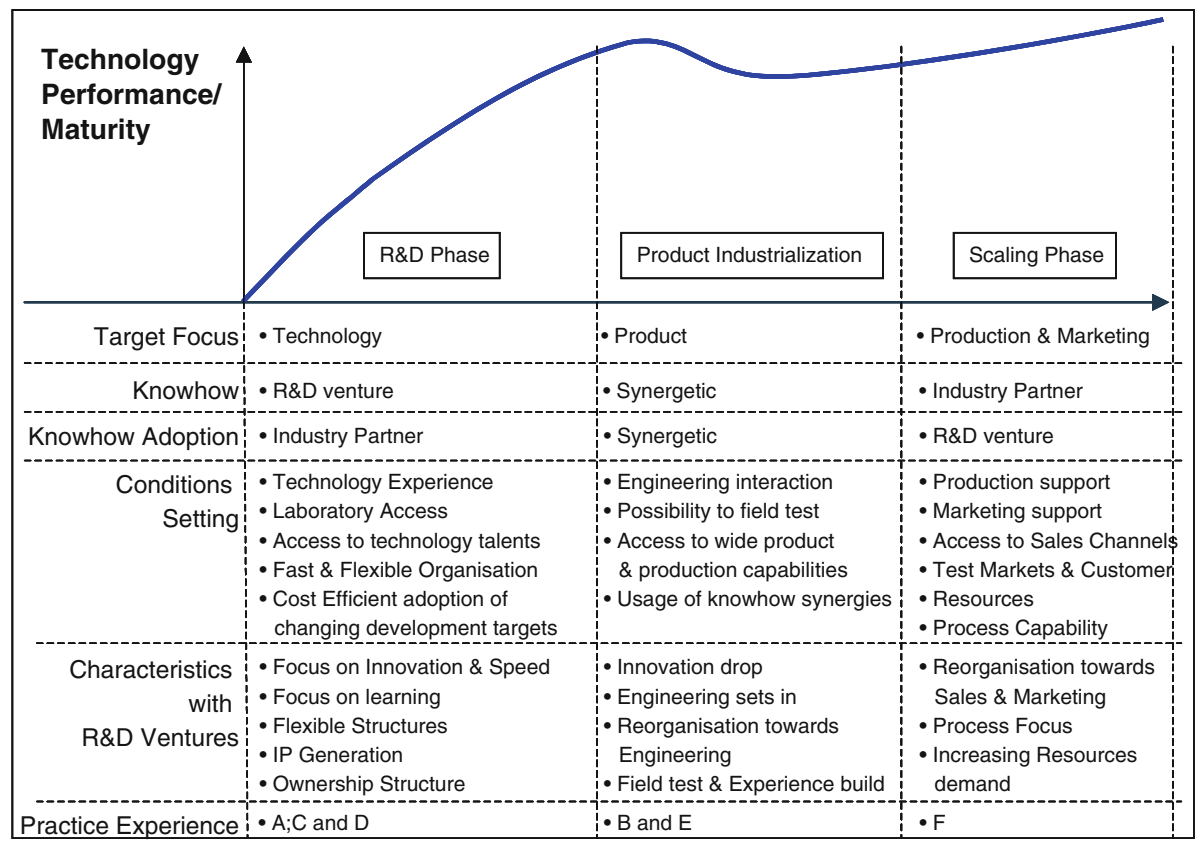

Fig. 8 Characteristics and experienced effects with R\&D Ventures 
Figure 8 summarizes the conditions set and the characteristics of R\&D Ventures as experienced by the partners involved. In the R\&D phase, the R\&D Venture owns the know-how, which is adopted by the industry partner. The environment is defined by the speed of innovation and by technology acumen. With product industrialization, a highly synergetic phase sets in where the industry partner supports the R\&D Venture with a wide range of industrialization know-how, engineering interaction and field-testing. Finally, in the scaling phase, the R\&D venture builds production, marketing and sales acumen from the product launch with the industry partner, which it can then leverage for customers from adjacent markets.

\subsection{Comparison with internal R\&D Projects}

Experience F: Internal versus external R\&D projects

R\&D Ventures are competitive or even better compared with internal industrial R\&D projects because... Entrepreneurial R\&D Venture environment close to academia

Clear target performance

Fast Innovation pace and efficient IP protection due to entrepreneurial product approach

Committed management incentivized on cost, staffing and time schedule

Control of cost and speed in the premature demonstration phase is critical

In order to demonstrate the innovation ramp-up of the R\&D Ventures' innovation network Fig. 9a, b shows a comparison of the industry partners' previous experience of running internal $R \& D$ projects of comparable size and technology life cycle with similar international patent classification. Neither of the projects selected were within the core competence of the $R \& D$ organization but were highly innovative. The projects were executed in the same entrepreneurial and $R \& D$ culture of the industry partner and have a similar technology life cycle, which allows a comparison and discussion.

The reconditioning project (Project I) was set up internally to develop the latest laser and scanning technology for the reconditioning of service parts. The internal monitoring project (Project II) was initiated to develop breakthrough monitoring and diagnosis systems
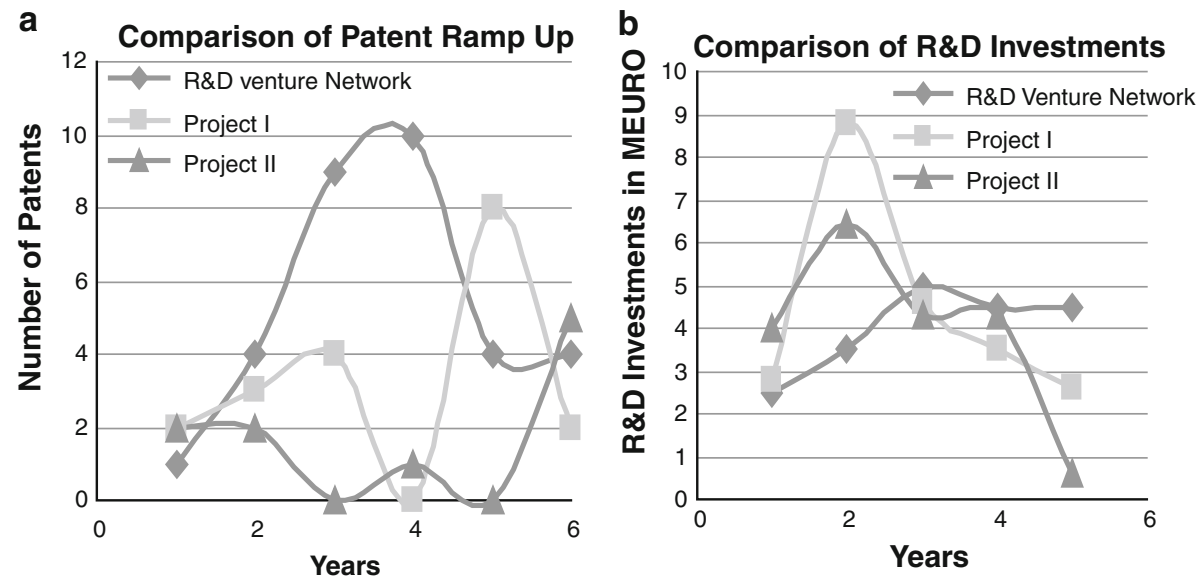

Fig. 9 a Comparison of number of patents between the R\&D Venture innovation network and internal R\&D projects of similar technology and size. $\mathbf{b}$ R\&D investments between the R\&D Venture innovation network and internal R\&D projects of similar technology and size 
for the service business, but due to internal reorganization it had been faded out of the research frame. Both R\&D projects deal with complex technical systems, are of a similar size to the R\&D Venture network, and deliver, or delivered, breakthrough innovation for the organization. However, it can be seen that the speed of innovation for the R\&D Ventures was nearly doubled. The five- to six-year time frame was considered sufficient to ramp up the breakthrough technologies, since all $R \& D$ Ventures and projects had reached a natural first innovation limit.

Interviews with R\&D management and Patent Management confirmed that the ramp-up by the $R \& D$ Ventures was received extremely quickly whereas the pattern of innovation in internal R\&D projects was just a normal part of their activities. The Patent Officer stated: "I can see no reason, why the internal projects are less innovative. All patents claims also of the $R \& D$ Ventures, are screened and evaluated by the patent board and need to achieve a degree of innovation to allow the cost of filing. Even if we are chasing the internal $R \& D$ organization we sometimes do not get sufficient early protection, patenting is often conceived additional work even if it is remunerated". Furthermore the Alpha CEO can be cited: "We have aggressively patented in order to protect our products using the Industry Partners IP validation Process". This states that the R\&D Ventures because of the entrepreneurial situation are far more aggressive in protecting intellectual property than the internal R\&D teams, which are only remunerated.

A strong, internal focus, with far less emphasis on academic input, capabilities and cooperation, as well as education time, the positioning of activities within the company, poorly adapted review processes and the ability of reviewers - all these prevented a fast ramp-up, explaining the cost differences shown. External sales of the R\&D investments for the R\&D Venture network were not taken into account, although during years four and five significant revenue was achieved, approaching the same range as the R\&D investments. The proven success factor for the R\&D Ventures was an entrepreneurial R\&D environment, defined by clear target performance and a management committed and incentivized on cost, staffing and time schedule. The control of cost and speed in the very early demonstration phase is critical. Small, agile entities with the appropriate management attendance have an obvious competitive advantage, when R\&D experience and resources are provided in a cooperation.

In interviews the R\&D Management emphasized on the experienced similarities between R\&D Ventures and internal R\&D programs: "The approach seems faster and cost effective, however the technology and product issues experienced are similar to our daily $R \& D$ live and are well known for an experienced $R \& D$ Manager".

\section{Framework and propositions for R\&D Ventures}

\subsection{Conceptual framework for R\&D Ventures}

Classifications of R\&D Ventures into common technology transfer channels are shown in Fig. 10. A generic technology maturity S-curve development over time has been underlaid with a qualitative technology development process. The phases describing the S-curve are derived and adapted from a wealth of literature (Marmer et al. 2011). It starts with the discovery phase, often in close cooperation with science and academia, where the innovation partner scouts for, screens and identificates potential innovation opportunities. In the validation phase, the innovation assessment and incubation of the technology are critical, where the potential value of the innovation is estimated and first business cases are 


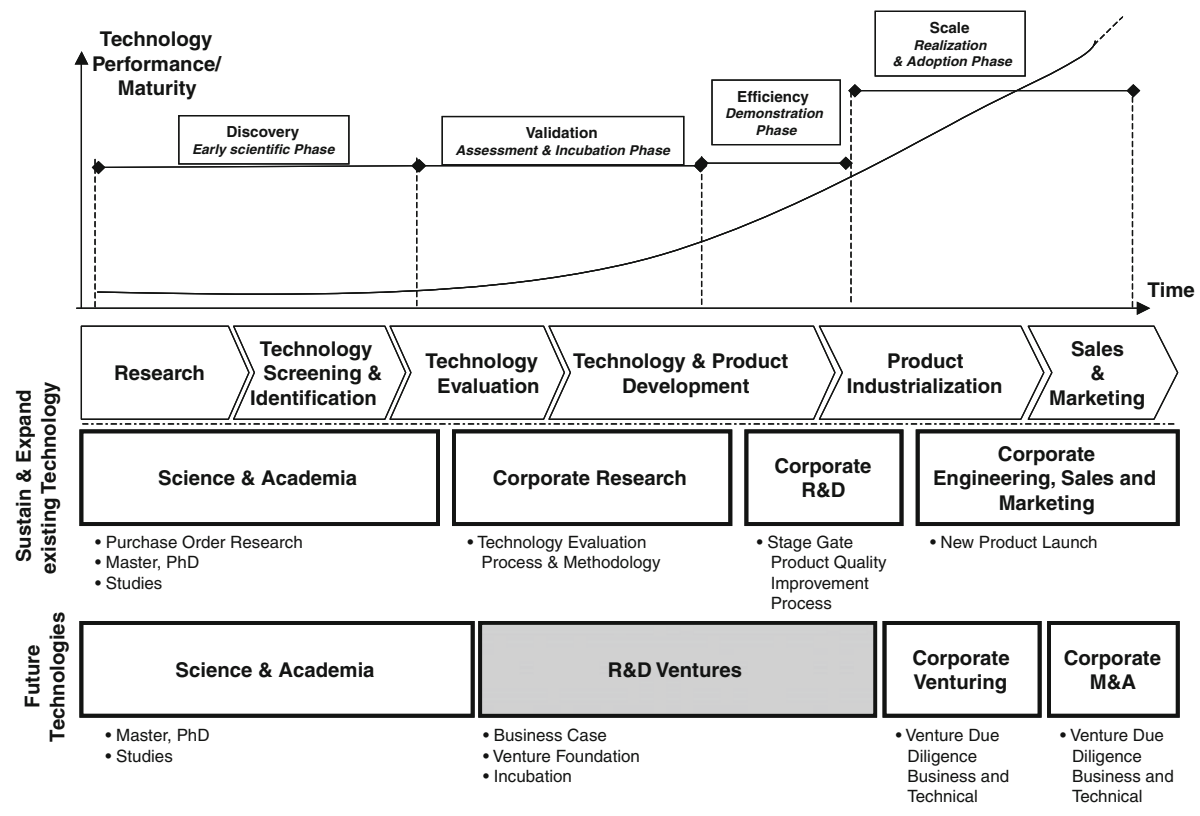

Fig. 10 Conceptual framework to classify and position R\&D Ventures

evaluated (Galbraith et al. 2006). The efficiency phase targets the refinement of the product in the demonstration and test phases in order to prepare a risk-mitigated scaling of the technology. The scaling phase starts to accelerate the production, industrialization, supply chain and marketing of the new technology launch. Every phase has a specific and important task to fulfill; the underlying processes rely on $\mathrm{R} \& \mathrm{D}$ experience and must be controlled with milestones and a defined scope of what is to be achieved. A badly managed process will usually be repaid with a high-risk exposure, often with product failure or the costs resulting from poor-quality, after-market introduction. (Marmer et al. 2011). All the R\&D Ventures discussed above have achieved the efficiency phase or more, in a variety of technologies.

When it comes to innovations which sustain and expand the existing technology portfolio, the corporate research organization is able to take them over directly from scientific and academic partners. It then pushes them along the established value chain, its prior experience and knowledge giving it confidence in its decision (Miotti and Sachwald 2003). Innovation partners, academia and industry are all used to this process (Morandi 2011); the interfaces are clearly defined in R\&D purchase orders and contracts, and the technology transfer is defined and takes place at the interface (Adams 2005).

As far as future technologies are concerned, there is a lack of capability for corporate research; in addition, the academic partner can only proceed as far as technology evaluation. Industrial R\&D experts are less confident and the trust they give internally is limited, owing to their lack of prior experience in the technology. The risks of innovation are considered high, supported by Siegel et al. (2003). Literature has shown that expert technology assessors and reviewers rate a "lengthy proposal, summary of the firm, team members, target market and technology" relatively low when they are predicting technology success (Galbraith et al. 2006, cited p. 681). The gap cannot easily be bridged by 
either of the partners, nor by corporate venturing or M\&A alone, as these can evaluate and invest but not deliver R\&D experience into the development phase with the necessary solid research and development capabilities (Andersson and Lööf 2011).

The experience practice discussed in Experience A "Dedicated R\&D Resources" and B "Technology Acceptance", supports that R\&D Ventures are an option to professionally try and test the technology in an incubation phase fast towards demonstrator (Di Guardo and Harrigan 2011), before committing on a business plan based on a technology assessment described above by Galbraith et al. (2006).

Particular in the validation phase corporate research can induce the assessment and incubation by initiating an $R \& D$ venture with academic partners, when the future technology development would be within a reasonable time frame, given by the organizations standard R\&D innovation cycles. After incubation, and moving towards the feasibility and demonstration phase, corporate venturing or the industrial partner's M\&A can take over to pursue engagement. In the scaling phase, the R\&D Venture may be acquired by the industrial partner, or sold back to management or to external investors, or it may be closed.

These are decisions strongly influenced by the board of the R\&D Venture. Research has shown that the composition of the board typically changes over the lifetime of the venture. Strongly impacted at first by the founding team and its technology capabilities, it separates into management team and board. The board takes on the advisory role and new members with market skills and supply chain expertise or corporate ventures will naturally occur during the course of development (Colombo et al. 2009). In a case study it has been shown that the process of forming a board is influenced by the board members' social network (Bjørnali and Gulbrandsen 2010). If there is an attempt to positively diffuse the venture technologies, the authors favor the involvement of corporate venturing suggested by Siegel et al. (2004). There is evidence that the acquisition of small, high-tech start-ups by large incumbent firms produces dismal results, as often the original inventors leave the company after acquisition (Colombo et al. 2009, p. 8). In any positive exit case, with the dilution of shareholders, the founding management must have an attractive ensured benefit, which should be properly defined in the shareholder agreement.

The exit phase has not been reached with any of the R\&D Ventures discussed, allowing room for further research. However, the board formation, and the changes discussed above, were in line with the behavior predicted by research.

\subsection{Propositions for R\&D Ventures}

The following set of proposition derived from the previous are discussed as following.

Proposition a For industries with strong external innovation pressure, $R \& D$ Ventures are a fast track to demonstrator stage and access to a future technology portfolio.

Where an industry has become stagnant, and a high level of growth in the established market is lacking, or if it is facing strong external innovation activities and demands like in the energy sector, the search and adoption of innovations are crucial for the established market player. (Schilling and Esmundo 2009; Mowery et al. 2010). As new innovation and market entrants like with new inspection technology but also with wind or solar technologies may challenge established positions, the discovery and pursuit of new opportunities, both internally and externally, is vital. (Barringer and Bluedorn 1999). The degree of the absorption level and the flexibility of the organization is critical for successful positioning. M\&A activities and corporate venturing allow the recognition and capturing of innovations and technologies which have achieved demonstration and are already visible in 
the market. (Bonardo et al. 2010). However, the number of transactions is limited because of size and risk exposure. Overpriced transactions, the possible discovery of "what has really been acquired," and integration issues all jeopardize the economic benefits.

Internal R\&D organizations can only explore the incremental expansion potential of the existing technology frame. (Henderson 1993; Ahuja and Lampert 2001). Experience F "Internal versus external R\&D projects" has shown an advantage of R\&D Ventures against internal $R \& D$ projects and that speed and agility to achieve demonstration of a new innovation opportunity in a future technology is important to reduce risk exposure and failure. Large industry inertia (Tornatzky and Fleischer 1990) can be compensated by an appropriate R\&D Venture set-up demonstrated by practice Experience A "Dedicated R\&D resources", C “Administration and Licensing". R\&D Ventures are an external opportunity for established industry to discover, develop and adopt innovation at an early, pre-demonstration stage; when it is accepted internally, and properly interacts with the R\&D organization, the absorption capability of an organization can be increased (Miotti and Sachwald 2003). Experiences B "Technology Acceptance" shows that interaction between the R\&D Venture and the industry increases acceptance and adoption of the breakthrough technology. R\&D Ventures are therefore applied when the technology does not expand the existing technology frame of a corporation but shows potential to fit into its future technology portfolio, within a reasonably short time. Industry should not found R\&D Ventures right at the beginning, but when the risk of working with independent start-ups as breakthrough innovation partners is too high, and a further control mechanism is needed, $\mathrm{R} \& \mathrm{D}$ Venturing is a promising option.

Proposition b For breakthrough innovation $R \& D$ Ventures are an opportunity for $R \& D$ cooperation with technology transfer between academia and industry.

In the early stages of technology innovation, academia can assume a sufficient overview of global publications in an innovation area, and is connected to relevant scientific players. A restricted ability to assess technology or to develop beyond science and education limit the success rate in technology transfer, although established industry partners may improve the evaluation process with technology and product development, production and market know-how. (Hall et al. 2001; O'Gorman et al. 2008). Therefore, cooperation between leading-edge technology know-how and product and market acumen is essential to successfully capture and explore early-stage future technologies. Technology identification, assessment and potential can be improved by a cooperative technology transfer approach between academia and industry partners.

Audretsch et al. (2002) and Siegel et al. (2004) have shown that cooperation between academia and industry partner improves productivity and patenting activity, whereas main interest for industry partner to cooperate is in access to key faculty personnel and students as potential employees. Experience A "Dedicated R\&D resources" and C "Administration and Licensing" show that access to talents and a trust building IP scheme are also success factors for the R\&D Venture approach. R\&D Ventures are set up as agile, entrepreneurial vehicles to increase performance of $R \& D$ cooperation for both technology transfer partners.

Proposition c $R \& D$ Ventures are an opportunity for young and talented entrepreneurs to start up technology ventures with increased speed in $R \& D$ cooperation with established industry and academia. 
Literature shows that entrepreneurs from academia often start up technology ventures at an early stage of technology maturity (Marmer et al. 2011), where the time to demonstrator stage and the target definition of the demonstrator remain unclear. The economical risk remains with the entrepreneurs. The practice Experience D "Innovation Drop" shows that shared product target definition and product development experience from established industry partners reduce the time and resources required. The growth impact on academic start-up firms is high when firms are able to detect, absorb and use the knowledge from academia (Colombo et al. 2010). Entrepreneurs benefit from fast, focused adoption of professional product development know-how, immediate product development target setting, reduction and sharing of development risks, access to academic talents and controlled resources ramp-up, as well as technology know-how and industrial experience. The R\&D Venture has direct access to the industrial partner if industrialization problems arise, and can directly involve the industrial knowledge sources via their connection to $R \& D$ management. Literature revealed the hurdles for independent scientific start-ups to approach the market (Marmer et al. 2011; Chandy and Tellis 2000). Experience E "Market Approach" shows the advantages for R\&D Ventures leveraging their alliance situation when approaching customers. This advantage particularly becomes vital for difficult markets with strong entry barriers like in the energy example, where already customer plant access can be a difficult barrier to overcome.

The R\&D Venture management benefits both from the development of the company, and if a dilution of capital trend sets in during the scaling phase, so that major investments have to be taken and original shareholders are washed out or turn into management positions. A clear evaluation of the company's value and its shares is essential to attract future talent, and has to be defined at the founding stage of the R\&D Venture.

\section{Discussions and conclusion for future research}

R\&D Venturing has been introduced and discussed as a practical phenomenon in the energy industry. It has been applied to improve the technology transfer for breakthrough innovation and future technologies and is focused on the early stages of technology discovery and evaluation towards demonstrator stage. It has been shown, that a R\&D cooperation with large industrial $R \& D$ organization and small agile ventures in the energy market with long product lead times can be successful. The authors argue that R\&D Venturing is a practical approach for the energy industry, particular because of its long development lead times with significant technology introduction risks. The R\&D Ventures build an entrepreneurial joint development vehicle, which allows exploring new technologies effectively and exploiting synergies in technology know how and market experience efficiently. With the characteristics shown in the case study presented agility and speed to technology demonstration and therefore the risk exposure of the partners will be reduced significantly. However interdependence, know-how exchange and thorough implementation of cooperation drivers are vital for the $R \& D$ venture concept regardless of the industry.

However the question if the conclusions above also hold true for other than the energy industry is essential. Recognizing the conceptual framework and propositions discussed in Fig. 10 as a valid opportunity to develop future breakthrough technologies with the R\&D Venture approach and realizing irregular dynamics of disruptive technology lifecycles in an industry, the need to identify a risk mitigating approach to demonstrate breakthrough technology is obvious. The authors would argue that the conclusions for the R\&D Ventures 
approach and its application are relevant when an industry faces irregular disruptive technology lifecycle dynamics with many potential breakthrough innovations coming up; too many to be explored within the enterprise internal R\&D resources focused on improving existing technologies and where speed to radical technology demonstration is crucial and a competitive advantage for the different players.

The R\&D Ventures discussed above have shown an improvement in performance and investment when compared with similar internal $R \& D$ projects for future technologies. The ramp-up of intellectual property and innovative technologies in the cases discussed has been faster and more cost efficient. The pace of delivery of new technologies to industrial partners and to market is advantageous. In an interview, R\&D Management compared R\&D Venturing as follows: "When a big army crosses a plain, it has an overview of the situation and moves as one, but when it enters a hilly landscape, it is wise to have small, fast search parties assessing the situation. That is $R \& D$ Venturing." Agility and speed are crucial. The leverage of R\&D investments and technologies developed into adjacent industries appears successful and the benefits are important. The ownership and share distribution between academia, venture management and industry has significant implications on R\&D Venture performance. A joint venture such as Alpha, with a majority share in the industrial partner, has advantages, like usage of brand and financial support, but also limits, including jeopardizing speed to demonstration, venture integration and financial consolidation. R\&D Ventures with a minority share, like Beta and Gamma, show a similar performance and are equally successful. A critical phase for R\&D Ventures is the assessment of the technology and the time frame needed to achieve demonstrator stage. This assessment drives the R\&D cost ramp-up and the payback expectations. Failure or misjudgment will jeopardize the success of the innovation activity. An integrative technology assessment and development with the partners is vital for success: only if the venture is given the chance to position itself efficiently in the center between academia and industry will it benefit from latest technology know-how and industry experience. In this matter, the R\&D Venture board plays an important role in helping the positioning between the players who align, control and guide the R\&D Venture and its development partners. Industry partners have to be aware of this role; relevant managers have to be convinced about the R\&D Venture approach and represented in positions of control. The speed of development is set by a clear target, which has been agreed in a commonly developed business case, an initial product strategy, and a strong integration of the R\&D Venture with academic and industrial partners. Public funding can be involved into the R\&D efforts without difficulty, as the eye-level cooperation between the partners is supportive for an SME environment and the future technology aspects of the set-up are immanent.

\subsection{Implication for research and practice}

This paper is based on case studies in the energy sector and conclusions must be drawn with care: generalizations drawn from what may be unique patterns can be misleading, and should be accompanied by knowledge of the cases discussed. However, the conceptual frameworks allow for deeper understanding of the principles of R\&D cooperation with R\&D Venturing, leverage the conclusions into other industries and may help to further conduct empirical research investigation. Research into the area of $R \& D$ Ventures will in any event be further conducted in coming years by the authors and the research team. The authors main focus of future R\&D Venturing research will be on the technology evaluation mechanism in the energy sector; the performance comparison of R\&D Ventures with standalone start-ups; the future set-up of technology organization; the management of a 
portfolio of R\&D Ventures and the incubation mechanism to share knowledge in an innovation and entrepreneurs' laboratory positioned between academia and industry.

Acknowledgments The authors acknowledge the valuable support and open access to information by all players in the R\&D Ventures, academia and the industry. We gratefully acknowledge the financial support of ETH Zürich and the industry partner.

\section{References}

Adams, J. D. (2005). Industrial R\&D Laboratories: Windows on black boxes. Journal of Technology Transfer, 30(1/2), 129-137.

Ahuja, G., \& Lampert, C. M. (2001). Entrepreneurship in the large corporation: A longitudinal study of how established firms create breakthrough inventions. Strategic Management Journal, 22, 521-543.

Andersson, M., \& Lööf, H. (2011). Small business innovation: Firm level evidence from Sweden. Journal of Technology Transfer. doi:10.1007/s10961-011-9216-9.

Audretsch, D., et al. (2002). The economics of science and technology. Journal of Technology Transfer, 27, $155-203$.

Barringer, B., \& Bluedorn, C. (1999). The relationship between corporate entrepreneurship and strategic management. Strategic Management Journal, 20, 421-444.

Belderbos, R., Carree, M., \& Lokshin, B. (2004). Cooperative R\&D and firm performance. Research Policy. doi:10.1016/j.respol.2004.07.003.

Bjørnali, E., \& Gulbrandsen, M. (2010). Exploring board formation and evolution of board composition in academic spin-offs. Journal of Technology Transfer, 35, 92-112.

Bojanowski, M., Corten, R., \& Westbrock, B. (2011). The structure and dynamics of the global network of inter-firm R\&D partnerships 1989-2002. Journal of Technology Transfer. doi:10.1007/s10961011-9234-7.

Bonardo, D., Paleari, S., \& Vismara, S. (2010). The M\&A dynamics of European science-based entrepreneurial firms. Journal of Technology Transfer, 35, 141-180.

Chandy, R. K., \& Tellis, G. J. (2000). The incumbent's course? Incumbent, size, and radical product innovation. Journal of Marketing, 64, 1-17.

Chesbrough, H. (2006). Open innovation. Boston, Massachusetts: Havard Business Review Press.

Christensen, C. (2003). The innovator's dilemma. New York: Harper Business Essentials Edition.

Cohen, W., \& Levinthal, D. (1989). Innovation and learning: The two faces of R\&D. The Economic Journal, 99(397), 569-596.

Colombo, M., D'Adda, D., \& Piva, E. (2010). The contribution of university research to the growth of academic start-ups: An empirical analysis. Journal of Technology Transfer, 35, 113-140.

Colombo, M., Mustar, P., \& Wright, M. (2009). Dynamic of science-based entrepreneurship. Journal of Technology Transfer, 35, 1-15.

Denzin, N., \& Lincoln, Y. (2005). The sage handbook of qualitative research. Thousand Oaks, California: Sage.

Di Guardo, M. C., \& Harrigan, K. R. (2011). Mapping research on strategic alliances and innovation: A co-citation analysis. Journal of Technology Transfer. doi:10.1007/s10961-011-9239-2.

Duncan, R. B. (1976). The ambidextrous organization: Designing dual structures for innovation. In R. H. Kilmann, L. R. Pondy \& D. Slevin (Eds.), The management of organizational design: Strategies and implementation (Vol. 1, pp. 167-188). New York: North Holland.

Dushnitsky, G., \& Lenox, M. (2005a). When do incumbents learn from entrepreneurial ventures? Corporate venture capital and investing firm innovation rates. Research Policy, 34, 615-639.

Dushnitsky, G., \& Lenox, M. (2005b). When do firms undertake R\&D by investing in new ventures? Strategic Management Journal, 26, 947-965.

Eisenhardt, K., \& Graebner, M. (2007). Theory building from cases, opportunities and challenges. Academy of Management Journal, 50(1), 25-32.

Ferrary, M. (2008). Strategic spin off: A new incentive contract for managing R\&D researchers. Journal of Technology Transfer, 33, 600-618.

Festel, G. (2009). Kommerzialisierung neuer Technologien durch gezielte start up Gründung, Das Founding Angles Geschäftsmodel. Zürich: Dissertation, Eidgenoessische Technische Hochschule.

Festel, G., \& Boutellier, R. (2009). Corporate FuE spin offs zur Steigerung der Innovationsfähigkeit. Wissenschaftsmanagement. 
Foster, R. (1987). Innovation: The attackers advantage. London: Pan Books.

Galbraith, C., Ehrlich, S., \& DeNoble, A. (2006). Predicting technology success: Identifying key predictors and accessing expert evaluation for advanced technologies. Journal of Technology Transfer, 31, 673-684.

Greenwood, D., \& Levin, M. (2007). Introduction to action research. Thousand Oaks, California: Sage.

Hall, B. H., Link, A. N., \& Scott, J. T. (2001). Barriers inhibiting from partnering with universities: Evidence from the advanced technology program. Journal of Technology Transfer, 26, 87-98.

Henderson, R. (1993). Underinvestment and incompetence as responses to radical innovation: Evidence from the photolithographic alignment equipment industry. RAND Journal of Economics, 24(2), 248-270.

Hussinger, K. (2010). Absorptive capacity and post-acquisition inventor Productivity. Journal of Technology Transfer. doi:10.1007/s10961-010-9199-y.

Kanter, R. (1985). Supporting innovation and venture development in established companies. Journal of Business Venturing, 1, 47-60.

Kathoefer, D. G., \& Leker, J. (2010). Knowledge transfer in academia: An exploratory study on the NotInvented-Here Syndrome. Journal of Technology Transfer. doi:10.1007/s10961-010-9204-5.

Katz, R., \& Allen, T. (1982). Investigating the Not Invented Here Syndrome: A look at the performance tenure and communication pattern of $50 \mathrm{R} \& \mathrm{D}$ Project Groups. R\&D Management, 12(1), 7-19.

Levinthal, D. A., \& March, J. G. (1993). The myopia of learning. Strategic Management Journal, 14, 95-112.

Liang, H., \& Zhang, Z. (2011). The effects of industry characteristics on the sources of technological product and process innovation. Journal of Technology Transfer. doi:10.1007/s10961-011-9206-y.

Marmer, M., Herrmann, B., \& Berman, R. (2011). Startup genome report 01, cracking the code of innovation. Stanford: University Report.

Masterplan Cleantech Schweiz (2010). Bern: Eidgenössisches Volkswirtschaftsdepartement EVD.

Meyer, M. (2006). Academic inventiveness and entrepreneurship: On the importance of start-up companies in commercializing academic patents. Journal of Technology Transfer, 31, 501-510.

Michl, T., Gold, B., \& Picot, A. (2010). Managing strategic ambidexterity: The spin along approach, CINet (pp. 750-763).

Miotti, L., \& Sachwald, F. (2003). Co-operative R\&D: Why and with whom? An integrated framework of analysis, Research Policy, 1697, 1-19.

Morandi, V. (2011). The management of industry-university joint research projects: How do partners coordinate and control R\&D activities? Journal of Technology Transfer. doi:10.1007/s10961-0119228-5.

Mowery, D.C., Nelson, R.R., \& Martin, B. (2010). Technology policy and global warming: Why new policy models are needed? Discussion. Research Policy, 39, 1011-1023.

O'Gorman, C., Byrne, O., \& Pandya, D. (2008). How scientists commercialize new knowledge via entrepreneurship. Journal of Technology Transfer, 33, 23-43.

Schilling, E., \& Esmundo, M. (2009). Technology S-curve in renewable energy alternatives: Analysis and implications for industry and government. Energy Policy, 37, 1767-1781.

Siegel, D., \& Wessner, C. (2010). Universities and the success of entrepreneurial ventures: Evidence from the small business innovation research program. Journal of Technology Transfer. doi:10.1007/s10961010-9186-3.

Siegel, D., et al. (2003). Commercial knowledge transfer from universities to firms: improving the effectiveness of university-industry collaboration. The Journal of High Technology Management Research, Pergamon, 14, 111-133.

Siegel, D., et al. (2004). Toward a model of the effective transfer of scientific knowledge from academicians to practioners: qualitative evidence from the commercialization of university technologies. Journal of Engineering and Technology Management, 21, 115-142.

Sohn, S. Y., \& Lee, M. (2011). Conjoint analysis of R\&D contract agreements for industry-funded university research. Journal of Technology Transfer. doi:10.1007/s10961-011-9220-0.

Sood, A., \& Tellis, G. (2005). Technological evolution and radical innovation. Journal of Marketing, 69, $152-168$.

Suarez, F., \& Lanzolla, G. (2007). The role of environmental dynamics in building a first mover advantage theory. Academy of Management Review, 32(2), 377-392.

Tornatzky, L., \& Fleischer, M. (1990). The process of technology innovation. Massachusetts: Lexington Books.

Tripsas, M. (2007). Customer preference discontinuities: A trigger for radical technological change. Managerial and Decision Economics, 29, 79-97. 
Woerter, M. (2011). Technology proximity between firms and universities and technology transfer. Journal of Technology Transfer. doi:10.1007/s10961-011-9207-x.

Wright, M., Clarysse, B., Mustar, P., \& Locket, A. (2007). Academic entrepreneurship in Europe. Northampton, Massachusetts: Edward Elgar Publishing Limited.

Yin, R. (2009). Case study action research, applied social research methods series (4th ed.). Thousand Oaks, California: Sage. 